\title{
MicroRNA-204 increases sensitivity of neuroblastoma cells to cisplatin and is associated with a favourable clinical outcome
}

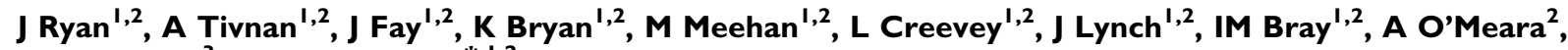 \\ AM Davidoff ${ }^{3}$ and RL Stallings ${ }^{*, 1,2}$
}

'Department of Molecular and Cellular Therapeutics, Cancer Genetics Research Group, Royal College of Surgeons in Ireland (RCSI), York House, York Street, Dublin 2, Ireland; ${ }^{2}$ National Children's Research Centre (NCRC), Our Lady's Children's Hospital, Crumlin, Dublin I2, Ireland; ${ }^{3}$ Department of Surgery, St. Jude Children's Research Hospital, 262 Danny Thomas Place, Memphis, TN 38105-3678, USA

\begin{abstract}
BACKGROUND: Neuroblastoma remains a major cause of cancer-linked mortality in children. miR-204 has been used in microRNA expression signatures predictive of neuroblastoma patient survival. The aim of this study was to explore the independent association of miR-204 with survival in a neuroblastoma cohort, and to investigate the phenotypic effects mediated by miR-204 expression in neuroblastoma.

METHODS: Neuroblastoma cell lines were transiently transfected with miR-204 mimics and assessed for cell viability using MTS assays. Apoptosis levels in cell lines were evaluated by FACS analysis of Annexin V-/propidium iodide-stained cells transfected with miR-204 mimics and treated with chemotherapy drug or vehicle control. Potential targets of miR-204 were validated using luciferase reporter assays. RESULTS: miR-204 expression in primary neuroblastoma tumours was predictive of patient event-free and overall survival, independent of established known risk factors. Ectopic miR-204 expression significantly increased sensitivity to cisplatin and etoposide in vitro. miR-204 direct targeting of the 3' UTR of BCL2 and NTRK2 (TrkB) was confirmed.

CONCLUSION: miR-204 is a novel predictor of outcome in neuroblastoma, functioning, at least in part, through increasing sensitivity to cisplatin by direct targeting and downregulation of anti-apoptotic BCL2. miR-204 also targets full-length NTRK2, a potent oncogene involved with chemotherapy drug resistance in neuroblastoma.

British Journal of Cancer (2012) I 07, 967-976. doi:I0.1038/bjc.2012.356 www.bjcancer.com
\end{abstract}

Published online 14 August 2012

(c) 2012 Cancer Research UK

Keywords: miR-204; neuroblastoma; BCL2; NTRK2; tumour suppressor; cisplatin

Neuroblastoma, a paediatric cancer of the sympathetic nervous system, is responsible for $15 \%$ of all childhood cancer-associated mortalities (Brodeur, 2003). A significant hallmark of the disease is the high level of heterogeneity with clinical outcome ranging from spontaneous remission to rapid progression and death. Currently, patients are identified as high-risk according to anatomical presence of disease at diagnosis (international neuroblastoma staging system, INSS), age, histology, and the presence of genetic features, including amplification of the MYCN oncogene, chromosome 11q deletion, and diploidy (Maris et al, 2007; Cohn et al, 2009; Maris, 2010). Although novel therapeutic approaches such as anti-GD2 immunotherapy have improved patient survival rates (2-year event-free survival (EFS) of $66 \%$ reported in high-risk neuroblastoma), 5-year survival rates are currently not available and this therapy has considerable deleterious side effects (Yu et al, 2010).

Although less favourable tumours initially respond well to induction chemotherapy therapy, the relapse rate is high, with relapse disease usually refractory to further treatment. Initial treatment may facilitate the selection of more resistant subclones existing within the population, but the mechanisms of resistance and relapse in neuroblastoma remain for the large part poorly

*Correspondence: Professor RL Stallings; E-mail: rstallings@rcsi.ie Received 23 April 2012; revised II July 2012; accepted 17 July 2012; published online 14 August 2012 understood. Evidence suggests that increased drug efflux through upregulation of ATP-binding transporter genes (often under the regulation of MYCN) represents one mechanism of resistance in high-risk neuroblastoma (Manohar et al, 2004; Porro et al, 2010). Epigenetic silencing through DNA hypermethylation of tumour suppressor genes in neuroblastoma has also been demonstrated as a mechanism of increased resistance to chemotherapy drugs (Teitz et al 2000; Charlet et al, 2012). Distinct specific mechanism of resistance in neuroblastoma include enhanced expression of BCL2 and NTRK2 (also known as TrkB). Reduced sensitivity to various chemotherapeutic drugs is mediated by high levels of the antiapoptotic protein BCL2 (Dole et al, 1994). NTRK2, a tyrosine kinase receptor for neurotrophins such as brain-derived neurotrophic factor (BDNF), also facilitates resistance to several chemotherapeutic agents through activation of the phosphatidylinositol 3'-kinase (PI3K)/Akt pathway (Ho et al, 2002).

The identification of additional independent biomarkers associated with survival, and elucidation of their function, may offer a greater insight into the underlying biology of disease, and the mechanisms of response to treatment and relapse. MicroRNAs (miRNAs), non-coding RNA molecules that regulate gene expression at the post-transcriptional level through sequence-specific base pairing with $3^{\prime}$ UTRs of target mRNA, have been linked to the development of drug resistance in several cancers (Giovannetti et al, 2012). Although a role for miRNAs in neuroblastoma cell resistance to chemotherapeutic drugs has not been reported, 
a number of studies have now identified miRNAs that are associated with poor clinical outcome in neuroblastoma (Chen and Stallings, 2007; Bray et al; 2009; Buckley et al, 2010; Mestdagh et al, 2010; Schulte et al, 2010), along with miRNAs that regulate a variety of processes, such as cell differentiation, apoptosis, proliferation, and invasiveness (Welch et al, 2007; Fontana et al, 2008; Foley et al, 2010, 2011; Bray et al, 2011; Lynch et al, 2012).

miR-204 has been used in miRNA expression signatures predictive of neuroblastoma patient survival (Bray et al; 2009; Schulte et al, 2010; De Preter et al, 2011). However, the independent significance of miR-204 in the outcome of neuroblastoma is unknown. Here, we report that miR-204 is a predictive determinant of outcome in neuroblastoma, with lower than median expression levels in tumours at diagnosis significantly associated with poor EFS and overall survival (OS). We demonstrate that while miR-204 has no effect in vivo or in vitro on neuroblastoma cell growth in the absence of any chemotherapeutic challenge, miR-204 increases sensitivity of neuroblastoma cell lines to cisplatin and etoposide. We demonstrate that this difference in sensitivity is due to increased levels of detectable apoptosis in miR-204-expressing cells following chemotherapy drug treatment. Finally, we determined that miR-204 directly targets the $3^{\prime}$ UTR of both the anti-apoptotic gene BCL2 and the oncogene NTRK2 (TrkB), both of which are significantly associated with poorer patient survival in neuroblastoma through increasing resistance to treatment (Dole et al, 1994; Ho et al, 2002), thus representing at least two distinct mechanisms where by miR-204 expression is associated with increased sensitivity of neuroblastoma cells to chemotherapy and improved patient survival.

\section{MATERIALS AND METHODS}

\section{Primary neuroblastoma tumours}

In total, 143 diagnostic primary neuroblastoma tumour samples were obtained from the Children's Oncology Group (COG), Philadelphia, PA, USA $(n=112)$ or from Our Lady's Children's Hospital, Dublin, Ireland $(n=31)$ (Supplementary Table 1). Research was approved by the Research Ethics Committees of the Royal College of Surgeons and Our Lady's Children's Hospital. Detailed miRNA expression profiling of this cohort of patients is described previously (Bray et al, 2009).

\section{Cell culture and transfections}

Neuroblastoma cell lines including Kelly (MYCN amplified), SK-NAS (non-MYCN amplified), and SHSY-5Y (non-MYCN amplified) were purchased from the European Collection of Animal Cells. $M Y C N$-amplified NB1691 cells were obtained from Dr Andrew Davidoff (St. Jude Children's Research Hospital, Memphis, TN, USA). All lines were validated by short tandem repeat sequence genotyping and for presence of previously published genomic imbalances using array comparative genomic hybridisation. Cell culture media was supplemented with $10 \%$ FBS and $1 \%$ Pen/Strep. miR-204 mimics and scrambled control oligonucleotides (Ambion, Life Technologies, Carlsbad, CA, USA) were transiently transfected into neuroblastoma cells at a final concentration of $30 \mathrm{~nm}$ by reverse transfection using siPORT NeoFX (Ambion). Small interfering RNAs (siRNAs; siRNA negative control and siBCL2 final concentration $30 \mathrm{nM}$ ) (Qiagen, Crawley, UK)), luciferase reporter plasmids, and miR mimics were transiently transfected into cells using Lipofectamine 2000 (Invitrogen, Carlsbad, CA, USA).

\section{Cell viability and apoptosis assays}

Viability of cells was measured by MTS-formazan reduction using CellTiter 96 Aqueous One Solution Cell Proliferation Assay (Promega, Madison, WI, USA) at 24, 48, 72, and $96 \mathrm{~h}$ post transfection.
Absorbance was measured at $490 \mathrm{~nm}$ using a Synergy Multi-Mode Plate Reader (Boitek, Winooski, VT, USA). Apoptosis levels were demonstrated by Annexin-V staining and propidium iodide (PI) exclusion using the FITC Annexin-V Apoptosis Detection Kit I (BD Pharmingen, San Diego, CA, USA). Cells were acquired using a BD LSR II flow cytometer (Becton Dickinson, San Jose, CA, USA) and analysed using BD FACSDiva 4.0 Software. Caspase 3 activity was evaluated using the Caspase-Glo 3/7 Assay (Promega) and luminescence recorded using a Synergy Multi-Mode Plate Reader (Boitek).

\section{Animal models}

Animal experiments were performed in 4-week-old CB-17/SCID mice (Charles River Laboratories, Wilmington, MA, USA) in accordance with protocols approved by the Institutional Animal Care and Use Committee of St Jude Children's Research Hospital, Memphis, TN, USA. The orthotopic xenograft model has been previously described (Dickson et al, 2007) (Supplementary Methods 1).

\section{Quantitative real-time RT-PCR}

Total RNA was extracted from cell lines using miRNeasy Mini Kits (Qiagen, Valencia, CA, USA). Reverse transcription was performed using total RNA with primers specific for miR-204 or U48 control and TaqMan microRNA reverse transcription kit (Applied Biosystems, Foster City, CA, USA). For gene expression analysis, reverse transcription was performed using High-Capacity reverse transcription kits (Applied Biosystems). Specific TaqMan assays (Applied Biosystems) for BCL2, NTRK2, and miR-204 were used for expression analysis on the 7900 HT Fast Realtime System (Applied Biosystems). MicroRNA and gene expression was normalised using the endogenous controls RNU48 and 18S, respectively, and relative quantities determined by the delta CT method.

\section{Western blot analysis}

Total protein was analysed by western blotting using primary antibodies anti-TrkB (G11) (Santa Cruz Biotechnology, Santa Cruz, CA, USA) and anti-BCL2 (Cell Signaling Technology, Beverly, MA, USA), followed by anti-mouse and anti-rabbit IgG HRP-conjugated secondary antibodies (Cell Signalling Technology).

\section{Luciferase reporter assay}

Direct targeting of $3^{\prime}$ UTRs was determined by cloning of the $3^{\prime}$-UTR seed region and a mutated seed region into separate psiCHECK-2 vectors (Eurofins MWG Operon, Anzingerstr, Ebersberg, Germany) for both BCL2 and NTRK2. Renilla and firefly luciferase activities were measured using the Dual-Luciferase Reporter kit (Promega) and luminescence recorded on a Synergy Multi-Mode Plate Reader (Boitek).

\section{Statistical analysis}

All statistical analyses were performed using GraphPad prism 5 software (GraphPad Software, San Diego, CA, USA) or MedCalc Version 12.2.1.0 (MedCalc Software, Mariakerke, Belgium). A $P$-value of $<0.05$ was regarded as statistically significant.

\section{RESULTS}

miR-204 expression is predictive of patient event-free and overall survival, independent of known risk factors

Analysis of miR-204 expression levels in 143 primary diagnostic neuroblastoma samples (Supplementary Table 1) revealed significantly 
A
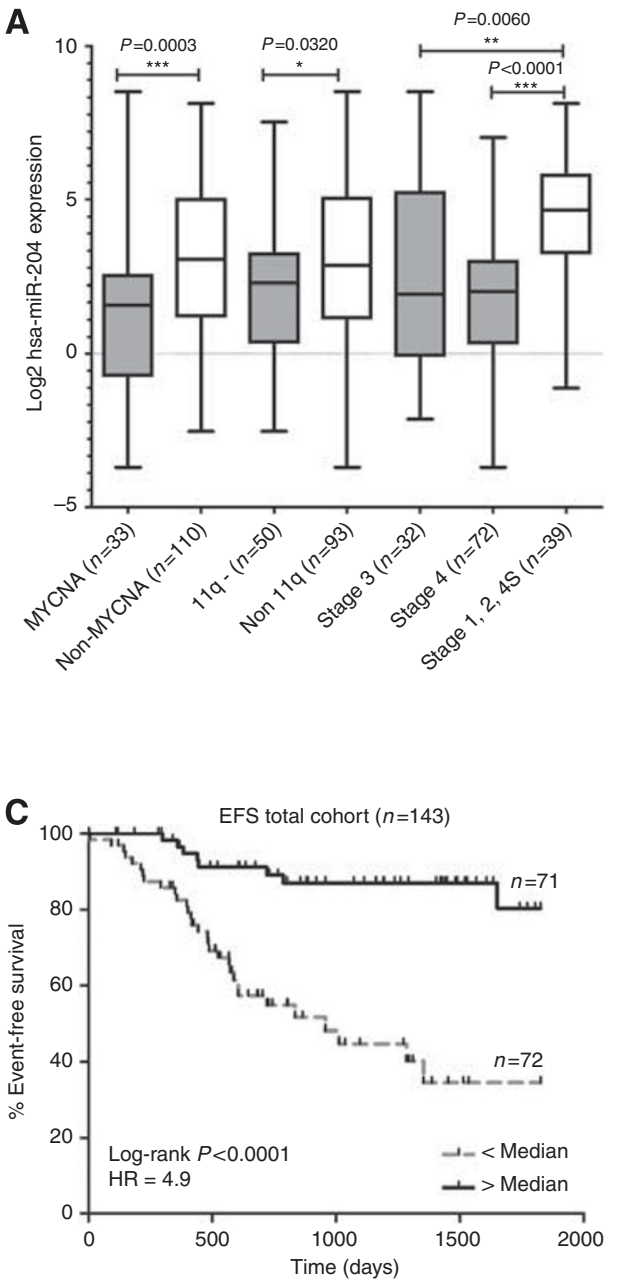

E

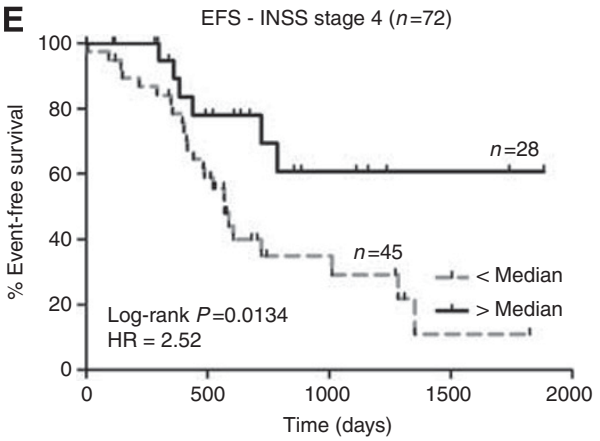

B

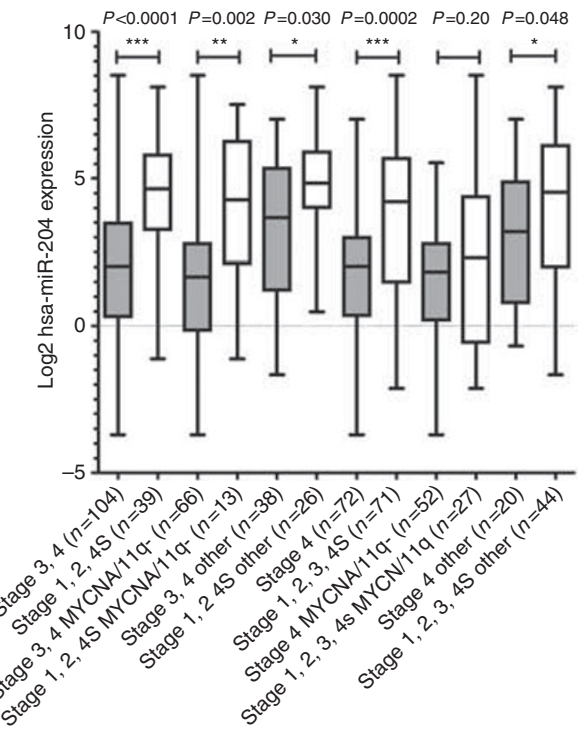

D

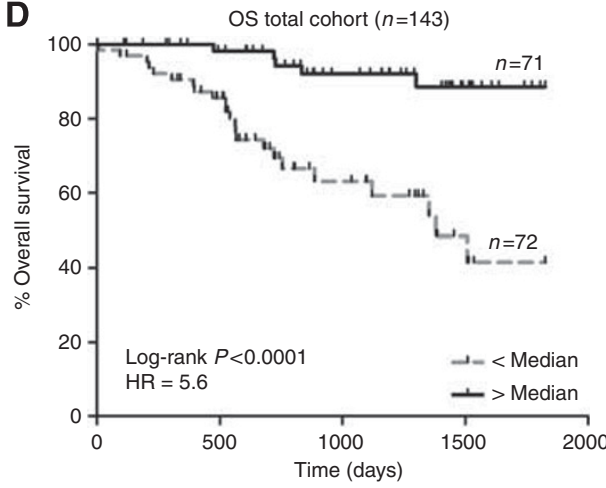

$\mathbf{F}$

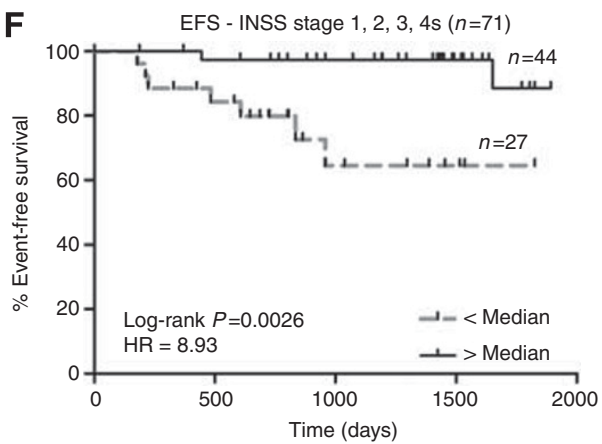

Figure I miR-204 expression is significantly associated with neuroblastoma disease subtypes and patient survival. (A) Box and whiskers plots represent the expression of miR-204 in a cohort of 143 primary neuroblastoma tumours. Samples are grouped according to known risk factors and miR-204 expression is compared between MYCN amplified (MYCNA) vs non-MYCNA, I I LOH vs non-I I q LOH, and INSS stages. Statistical differences in median expression were analysed using two-sided Mann-Whitney $U$ tests. Dark shading indicates known higher-risk factor. (B) Expression of miR-204 in higher-risk INSS stages 3 and 4 vs lower-risk stages I, 2, 4S, and in high-risk INSS stage 4 vs stage I, 2, 3, 4S tumours. Samples are further grouped according to the presence of MYCNA and/or I I LOH (MYCNA/ I I q-) and non-MYCNA and I I q LOH (designated as 'other'). (C, D) Kaplan-Meier plots for EFS and OS in 143 neuroblastoma patients, with miR-204 expression > or < median. P-values were obtained using log-rank test. (E) Kaplan-Meier plots for EFS in highrisk INSS stage 4 disease $(n=72)$ with miR-204 expression $>$ or $<$ median. (F) Kaplan-Meier plots for EFS in lower-risk INSS stage I, 2, 3, 4S disease $(n=7 \mathrm{I})$ with miR-204 expression $>$ or $<$ median. Abbreviation: HR $=$ hazard ratio.

lower expression of miR-204 in patients with known higher-risk prognostic factors including MYCN amplification, 11q- deletion, and INSS stage 3 or 4 disease (Figure 1A). In samples stratified according to INSS stage, the expression of miR-204 remained significantly lower in stage 3 and/or stage 4 tumours irrespective of $M Y C N$ or $11 \mathrm{q}$ status, consistent with an independent predictive power (Figure 1B).
In univariate survival analysis, miR-204 was significantly associated (log-rank $P<0.0001$ ) with both EFS and OS, with $>$ median expression of miR-204 indicative of improved survival (EFS HR 4.9, 5-year EFS 34.5\% vs 80.3\%; OS HR 5.6, 5-year OS $41.5 \%$ vs $81.6 \%$ ) (Figure $1 \mathrm{C}$ and $\mathrm{D}$ ). Multivariate Cox regression analysis of time to EFS excluded the variables of patient age, MYCN status, and 11q status in a stepwise prediction model of 
Table I Univariate (Kaplan-Meier) and multivariate (Cox proportional hazard regression) analysis of event-free survival in I43 neuroblastoma patients

\begin{tabular}{|c|c|c|c|c|c|c|c|c|c|c|}
\hline \multirow{2}{*}{ Variable } & \multirow{2}{*}{$n$} & \multicolumn{3}{|c|}{ Univariate $^{a}$} & \multicolumn{6}{|c|}{ Multivariate $^{b}$} \\
\hline & & HR & $95 \% \mathrm{Cl}$ & EFS $P$ & \multicolumn{3}{|c|}{ Entered } & \multicolumn{3}{|c|}{ Stepwise $^{c}$} \\
\hline \multicolumn{11}{|l|}{ INSS } \\
\hline Stage 4 & 72 & 6.59 & $3.3-12.9$ & $<0.0001$ & 3.10 & 1.3-7.3 & 0.0095 & 5.25 & $2.4-11.4$ & $<0.0001$ \\
\hline Stage $1,2,3,4 \mathrm{~S}$ & 71 & I & & & I & & & 1 & & \\
\hline \multicolumn{11}{|l|}{ Age } \\
\hline$\geqslant 1$ year & 123 & 2.42 & I.I-5.4 & 0.0331 & 2.69 & $0.6-11.7$ & 0.1815 & - & - & - \\
\hline$<$ I year & 20 & 1 & & & 1 & & & & & \\
\hline \multicolumn{11}{|l|}{ MYCN } \\
\hline Amplified & 33 & 3.7 & $1.7-8.1$ & 0.0011 & 1.80 & $0.9-3.8$ & 0.1187 & - & - & - \\
\hline No deletion & 93 & I & & & 1 & & & & & \\
\hline \multicolumn{11}{|l|}{ MiR-204 } \\
\hline Low expression & 72 & 4.89 & $2.5-9.3$ & $<0.0001$ & 2.61 & I.I-5.8 & 0.0206 & 3.13 & $1.69-7.9$ & 0.0011 \\
\hline High expression & 71 & 1 & & & 1 & & & I & & \\
\hline
\end{tabular}

Abbreviations: $\mathrm{EFS}=$ event-free survival; HR = hazard ratio; INSS = international neuroblastoma staging system; $95 \% \mathrm{Cl}=95 \%$ confidence interval. ${ }^{2}$ Kaplan-Meier $P$-values for EFS $=$ log-rank. ${ }^{b}$ Variables entered in Cox proportional hazard model: mIR-204 expression (low expression < median, high expression > median), INSS (stage 3 and 4 , stages I, 2, 4S and stage 4, stages I, 2, 3, 4S), age ( $\geqslant$ I year, <I year), MYCN amplified (yes, no) and chromosome I I q deleted (yes, no). 'The variables age, MYCN status, I I q status and INSS stage 3, 4 vs stage I, 2, 4S were found not to significantly contribute to the prediction of EFS time and were excluded in the stepwise Cox multivariate model.

survival time, leaving only INSS stage $4 v s$ stages $1,2,3,4 \mathrm{~S}$ and $>/<$ median miR-204 expression as significant contributing variables (Table 1). In univariate survival analysis of stagestratified patients, greater than median expression of miR-204 was significantly associated with improved EFS and OS in highrisk INSS stage 4 disease (EFS HR 2.53, 5-year EFS 11\% vs 61\%; OS HR 2.46, 5-year OS $10 \%$ vs 47\%), and in stage 1, 2, 3, 4S disease (HR 8.9, 5-year EFS 64.5\% vs 88.5\%; OS HR 18, 5-year OS 79\% vs $100 \%)$, indicating a degree of independence of miR-204 expression in determining time to relapse (Figure $1 \mathrm{E}$ and $\mathrm{D}$ ).

\section{Ectopic miR-204 expression increases sensitivity of neuroblastoma cells to cisplatin in vitro}

Given the significant association of low miR-204 expression with poor patient survival, we investigated the effects on viability of miR-204 ectopic expression in neuroblastoma cells by transiently transfecting mature miR-204 mimics into Kelly, NB1691, SK-N-AS, and SHSY-5Y cell lines. Although miR-204 expression was significantly upregulated following transfection in all cell lines (Supplementary Figure 1), we observed no discernable effect on cell viability, as determined by MTS assays, relative to negative controls (Supplementary Figure 2A). Transfection of miR-204 mimics into the NB1691 luc and SK-N-AS ${ }^{\text {luc }}$ cells before their implantation into the retroperitoneal space of SCID mice also had no impact on tumour establishment or growth in vivo (Supplementary Figure 2B).

In order to elucidate how higher miR-204 might contribute to improved patient survival, we assessed the effect of miR-204 overexpression on the response of two $M Y C N$-amplified cell lines (Kelly and NB1691) to the chemotherapy drug cisplatin (CDDP), commonly used in the treatment of neuroblastoma. Kelly and NB1691 cells were transfected with miR-204 mimics and exposed to concentrations of CDDP ranging from 0 to $50 \mu \mathrm{g} \mathrm{ml}^{-1}$. The survival of miR-204-transfected cells relative to the negative control, as determined by MTS assays, was signifi- cantly lower at concentrations of 1 and $5 \mu \mathrm{g} \mathrm{ml}^{-1} \mathrm{CDDP}$ in Kelly cells (Figure 2A), and at $5 \mu \mathrm{g} \mathrm{ml}^{-1} \mathrm{CDDP}$ in NB1691 cells (Figure 2B). These observations were confirmed in further independent experiments using $5 \mu \mathrm{g} \mathrm{ml}^{-1} \mathrm{CDDP}$ treatment (mean differences in cell viability; Kelly $8.94 \pm 2.3 \% P<0.001$, NB1691 8.2 $\pm 2.6 \% P<0.01$ ) (Figure 2C and D).

Through in silico analysis (using the algorithms PicTar, TargetScan, and miRanda), we examined all computationally predicted target genes of miR-204. There was 107 targets common to all three algorithms (Supplementary Figure 3 and Supplementary Table 2). BCL2 was a target of interest owing to its known role in increased resistance to CDDP-triggered apoptosis in neuroblastoma. To test the hypothesis that miR-204 targeting of $B C L 2$ may account for the observed increase in sensitivity to CDDP, we performed siRNA-mediated inhibition of BCL2 in parallel with miR-204 overexpression. BCL2 was significantly reduced at mRNA and protein levels following siBCL2 transfection (Supplementary Figure 4). In the absence of CDDP treatment, BCL2 knockdown resulted in significantly decreased survival of Kelly cells, but not NB1691 cells (Figure 2C and D). However, treatment of both cell lines with $5 \mu \mathrm{g} \mathrm{ml}^{-1} \mathrm{CDDP}$, following siRNA knockdown of BCL2, resulted in significantly decreased cell viability relative to negative controls for both cell lines (mean differences; Kelly $14 \pm 2.0 \% \quad P<0.0001 ; \quad$ NB1691 $14.6 \pm 2.9 \%$ $P<0.0001)$, similar to the response seen in cells overexpressing miR-204 (Figure 2C and D).

To confirm that siRNA-mediated inhibition of $B C L 2$ enhanced CDDP-mediated apoptosis, and to investigate if decreased viability owing to overexpression of miR-204 was due to a similar increase in apoptosis levels, caspase 3/7 and Annexin V/PI assays were performed. Kelly cells transfected with either miR-204 mimics or siBCL2 displayed significantly increased caspase 3/7 activation within $72 \mathrm{~h}$ post transfection and following treatment with $5 \mu \mathrm{g} \mathrm{ml}^{-1}$ CDDP (Figure 3A), consistent with results from MTS viability experiments. Apoptosis levels determined by Annexin V/PI staining and FACs analysis confirmed that the observed increases in 

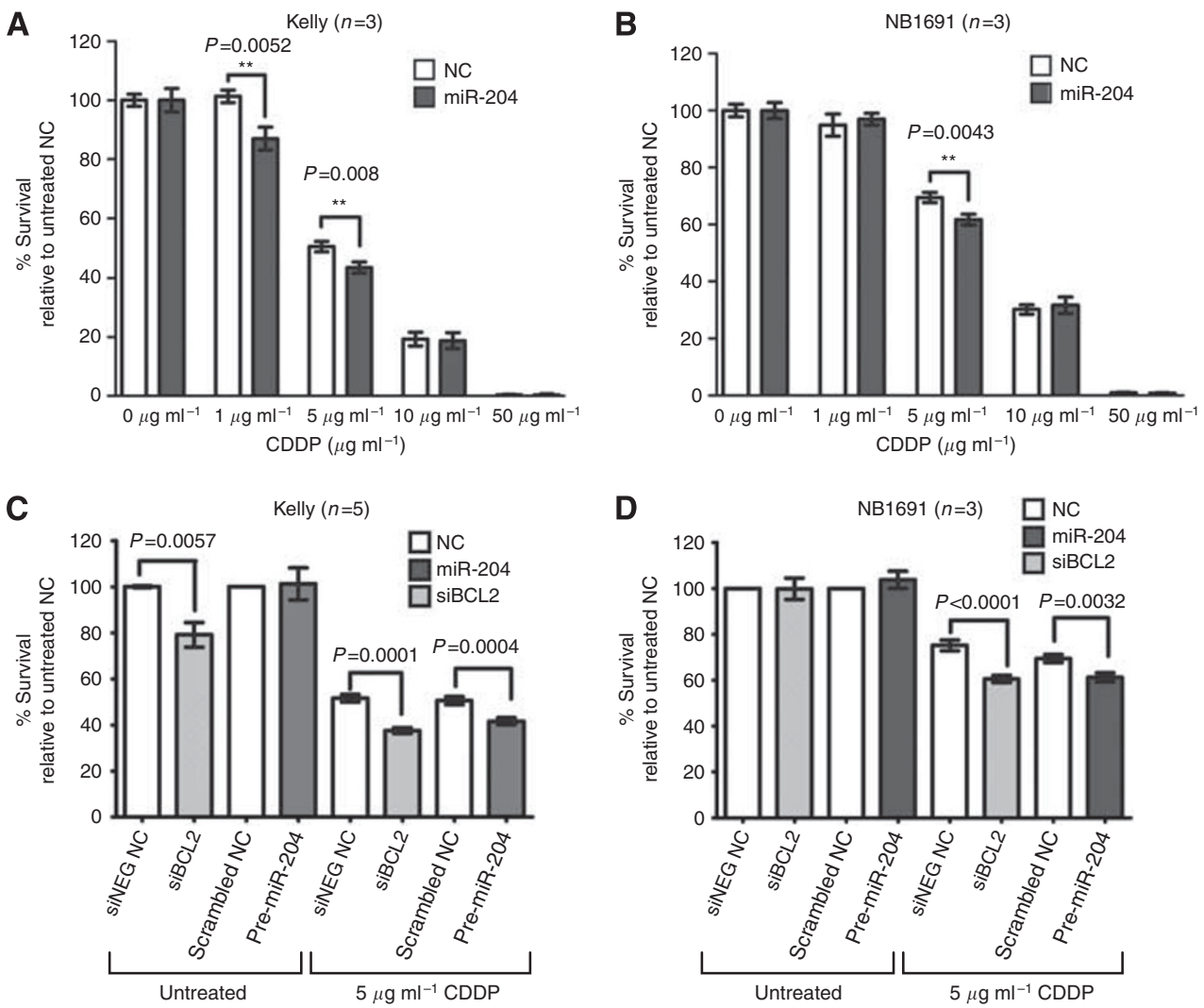

Figure 2 Ectopic expression of miR-204 in neuroblastoma cell lines increases sensitivity to cisplatin (CDDP) in vitro. (A, B) Neuroblastoma MYCNamplified cell lines Kelly and NBI69 I were transfected with miR-204 mimics or scrambled negative control (NC) oligonucleotides. At $48 \mathrm{~h}$ post transfection, cells were treated for $24 \mathrm{~h}$ with 0 to $50 \mu \mathrm{g} \mathrm{ml}{ }^{-1}$ CDDP. Media were replaced for a further $24 \mathrm{~h}$, and viability determined at $96 \mathrm{~h}$ by MTS assays. (C, D) Kelly and NBI69| cells were transfected with an siRNA targeting BCL2 or a siRNA negative control oligonucleotide (siNEG NC), or miR-204 mimics or scrambled negative control (scrambled NC) oligonucleotides. At $48 \mathrm{~h}$ post transfection, cells were treated for $24 \mathrm{~h} \mathrm{with} \mathrm{or} \mathrm{without} 5 \mu \mathrm{g} \mathrm{ml}{ }^{-1} \mathrm{CDDP}$. Media were replaced for a further $24 \mathrm{~h}$, and viability determined at $96 \mathrm{~h}$ by MTS assays. Percentage survival was determined relative to either untreated siNEG NCs or untreated scrambled NCs. All graphed values represent (mean value \pm s.e.m.) biological replicate experiments $(n=3-5)$ with six technical replicates, and differences in viability were analysed by two-sided Student's $t$-tests.

caspase activity translated to increased apoptotic rates in Kelly cells. Following treatment with $5 \mu \mathrm{g} \mathrm{ml}^{-1} \mathrm{CDDP}$, significantly increased levels of early apoptosis (Annexin $\mathrm{V}+/ \mathrm{PI}-$ ) and late (Annexin $\mathrm{V}+/ \mathrm{PI}+$ ) apoptosis were observed in miR-204 overexpressing cells, and in siBCL2 transfected cells, relative to the negative controls at $72 \mathrm{~h}$ (Figure $3 \mathrm{~B}$ and $\mathrm{C}$ ). Apoptosis levels were further enhanced at $96 \mathrm{~h}$ post transfection with $5 \mu \mathrm{g} \mathrm{ml}^{-1} \mathrm{CDDP}$ treatment (Supplementary Figure 5). We conclude that miR-204, through enhanced apoptosis, significantly increases sensitivity of neuroblastoma cells to cisplatin in vitro.

To investigate if overexpression of miR-204 affected apoptosis of cells to chemotherapy challenge other than CDDP, we exposed cells to the topoisomerase II inhibitor etoposide (VP-16), also commonly used in the treatment of neuroblastoma. Following treatment with $10 \mu \mathrm{g} \mathrm{ml}^{-1} \mathrm{VP}-16$, modest but significantly increased levels of apoptosis (Annexin $\mathrm{V}$ positive: $33 \pm 4 \%$ vs $23 \pm 2.4 \% P=0.045)$ were observed in miR-204 overexpressing Kelly cells, relative to the negative controls at $96 \mathrm{~h}$ (Supplementary Figure 6).

\section{miR-204 targets BCL2 and TrkB in neuroblastoma cell} lines

Given that siRNA-mediated inhibition of $B C L 2$, a computationally predicted target of miR-204, had a similar phenotypic effect on CDDP drug sensitivity as miR-204 overexpression, we decided to experimentally validate $B C L 2$ as a miR-204 direct target. BCL2 has a highly conserved 7 mer seed match with miR-204 in its $3^{\prime}$ UTR (Figure 4A). Ectopic overexpression of miR-204 mimics in Kelly cells resulted in a knockdown of BCL2 protein but not mRNA, indicating that the miRNA had a potential inhibitory effect on translation (Figure 4B).

To determine if miR-204 directly targets the $3^{\prime}$ UTRs of $B C L 2$, luciferase reporter plasmids were constructed containing a 450-bp segment of the $B C L 23^{\prime}$ UTR with either the wild-type or a mutated miR-204 seed site (Supplementary Figure 7). Cotransfection of the reporter construct containing the wild-type-binding sequence with mature miR-204 mimics resulted in a statistically significant reduction in luciferase activity in Kelly cells (Figure 4C). This effect was abrogated by a mutated target sequence, thereby confirming that BCL2 is directly targeted by miR-204.

Another computationally predicted target of interest was NTRK2, a tyrosine kinase receptor for several neurotrophins such as BDNF, NT-3, and NT-4. The full-length NTRK2 mRNA is expressed at higher levels in unfavourable tumour subtypes (Matsumoto et al, 1995), and NTRK2 protein (with intact tyrosine kinase domain) increases resistance of neuroblastoma cells to chemotherapeutic drugs, including CDDP (Ho et al, 2002; Jaboin et al, 2002). NTRK2 has one highly conserved $7 \mathrm{mer}$ seed match and two poorly conserved 7 mer matches with miR-204 in its $3^{\prime}$ UTR (Figure 4D).

Analysis of the impact of miR-204 on endogenous levels of NTRK2 mRNA and protein in neuroblastoma cells was complicated by the fact that the full-length NTRK2 is rarely detected in neuroblastoma 
A

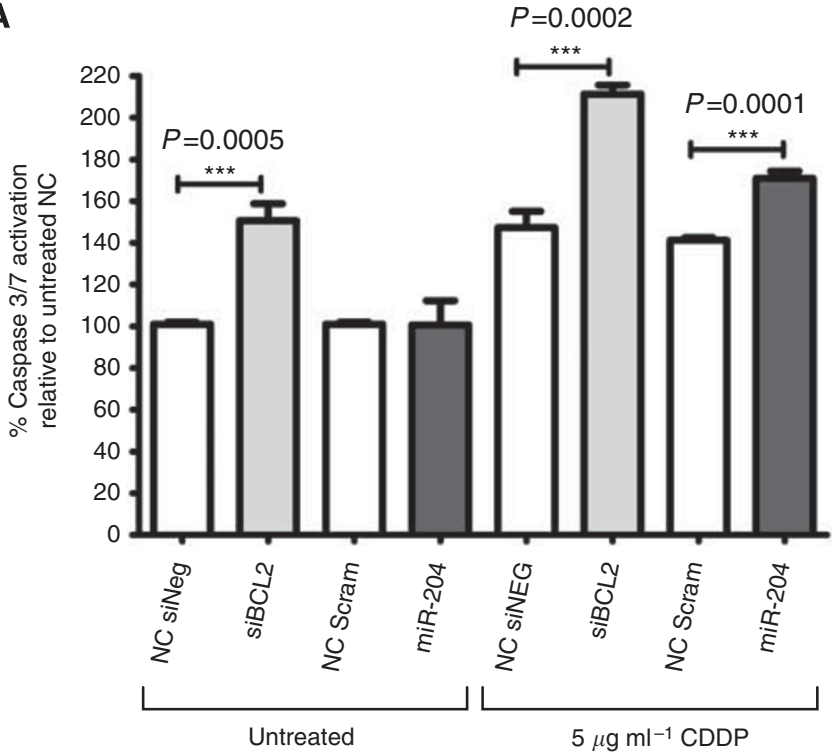

B

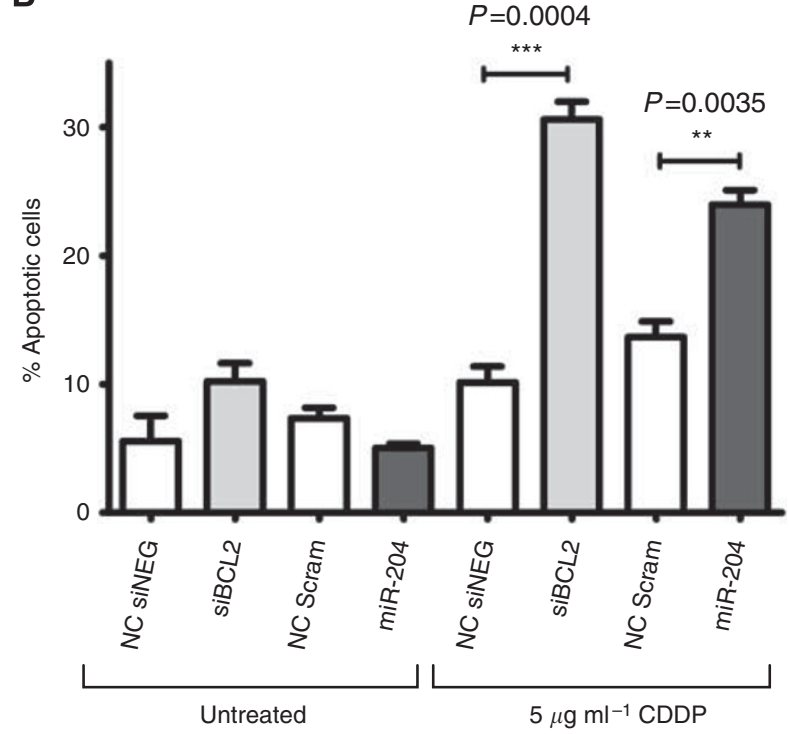

C

No CDDP - $72 \mathrm{~h}$ post transfection
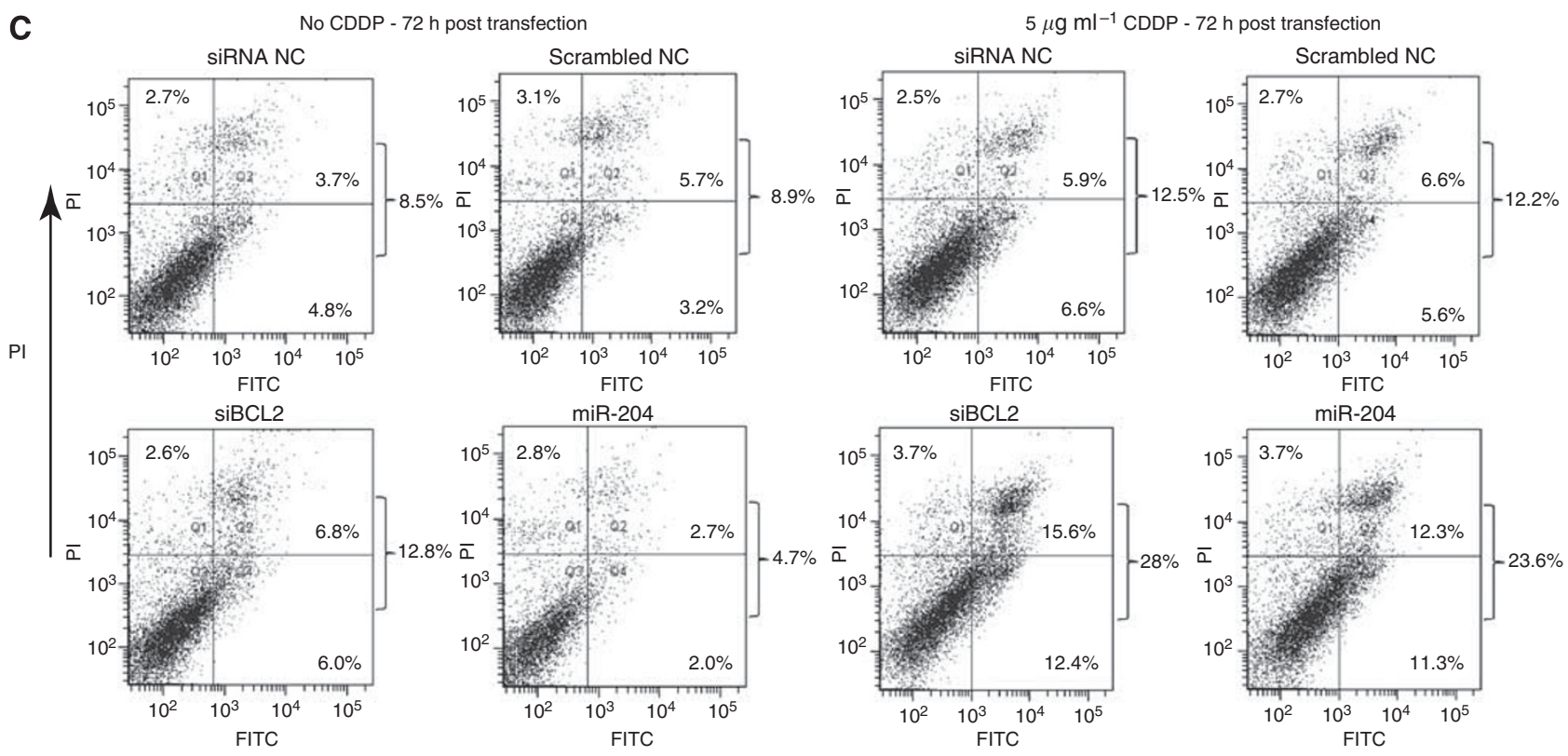

$5 \mu \mathrm{g} \mathrm{ml}^{-1} \mathrm{CDDP}-72 \mathrm{~h}$ post transfection
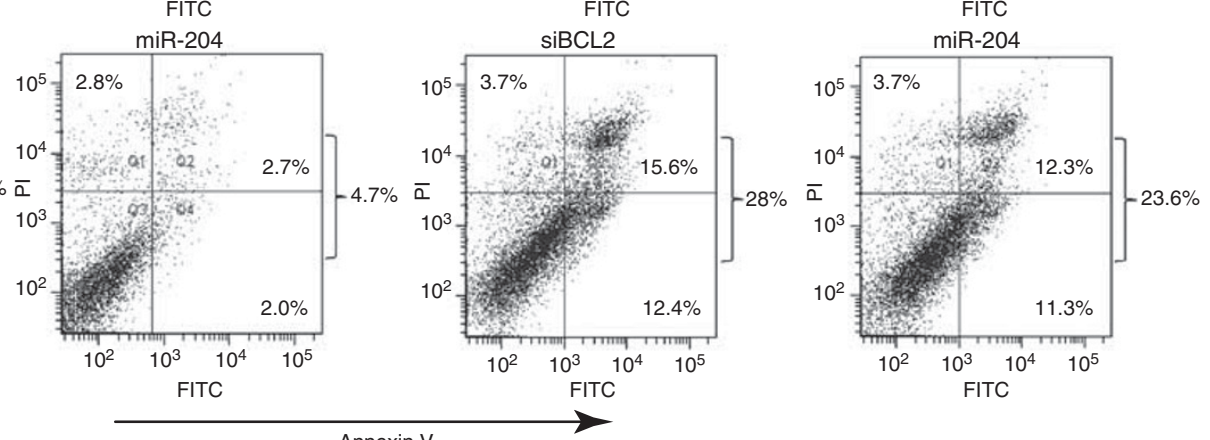

Annexin V

Figure 3 miR-204 increases apoptotic levels of neuroblastoma cells following treatment with CDDP. Kelly cells were transfected with siRNA targeting BCL2 or siRNA negative control oligonucleotide (siNEG NC), or miR-204 mimics or scrambled negative control (scrambled NC) oligonucleotides. At $48 \mathrm{~h}$ post transfection, cells were treated for $24 \mathrm{~h}$ with or without $5 \mu \mathrm{g} \mathrm{ml}{ }^{-1}$ CDDP. Graphed data are mean values \pm s.e.m. of at least three biological replicate experiments. $P$-values were determined using two-sided Student's $t$-tests. (A) Caspase 3/7 activation was measured at $72 \mathrm{~h}$ post transfection ( $n=3$, with five technical replicates). (B) Mean percentage of annexin $\mathrm{V}$-positive Kelly cells from at least three independent experiments at $72 \mathrm{~h}$ post transfection with siBCL2/siNEG NC, or miR-204 mimic/scrambled NC and with/without $5 \mu \mathrm{g} \mathrm{ml}{ }^{-1}$ CDDP treatment. (C) Representative scatter plots of PI vs Annexin V-FITC staining in one independent experiment with Kelly cells at $72 \mathrm{~h}$.

cell lines, even though this variant is usually expressed at high levels in unfavourable tumour subtypes. To overcome this, we stimulated the cells for $48 \mathrm{~h}$ with $5 \mu \mathrm{m}$ all-trans retinoic acid (ATRA) to induce the expression of full-length NTRK2 (Middlemas et al, 1999) following transfection of SHSY-5Y cells with miR-204 mimics. Ectopic expression of miR-204 resulted in significant knockdown of NTRK2 at both mRNA and protein levels following expressional induction by ATRA (Figure 4E).

Luciferase reporter plasmids containing a 499-bp segment of the NTRK2 $3^{\prime}$ UTR with either the wild-type or a mutated 8mer seed site for miR-204 were then used to determine if this miRNA directly targets NTRK2 (Supplementary Figure 7). Cotransfection of the reporter construct containing the wild-typebinding sequence with mature miR-204 mimics resulted in a statistically significant reduction in luciferase activity in Kelly cells (Figure 4F). This effect was abrogated by a mutated target sequence, thereby confirming that NTRK2 is directly targeted by miR-204.

Owing to the lack of full-length NTRK2 expression in our cell lines, we were aware that our observed effects of miR-204 on 
A
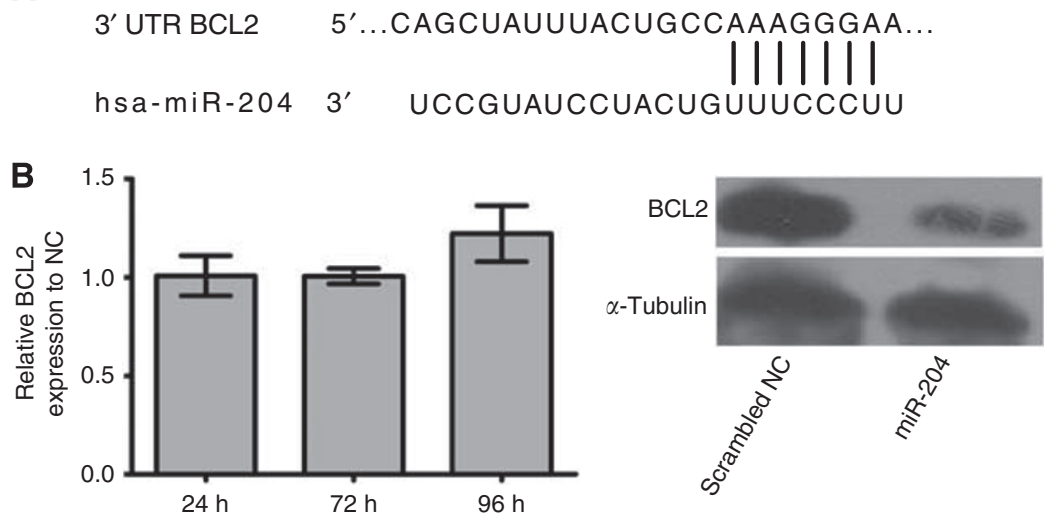

D
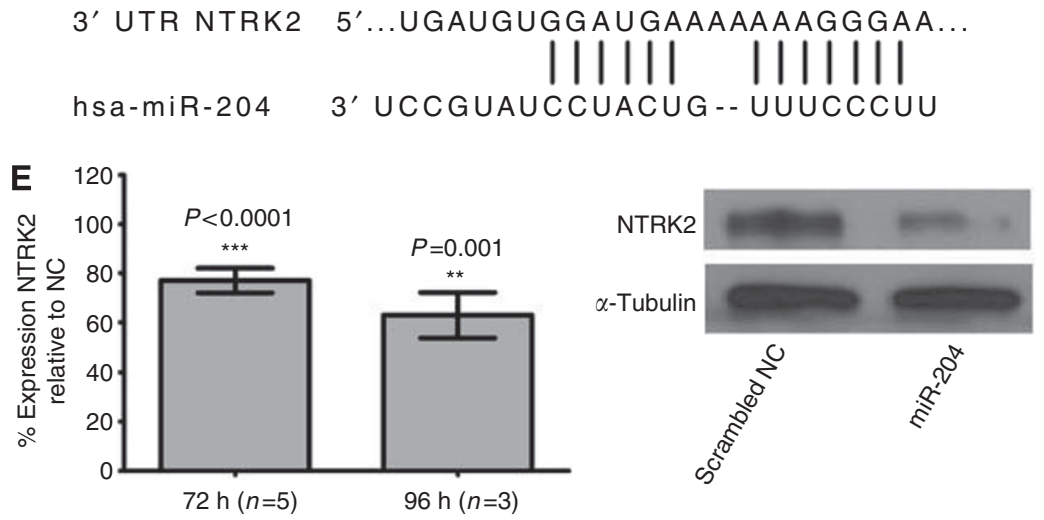

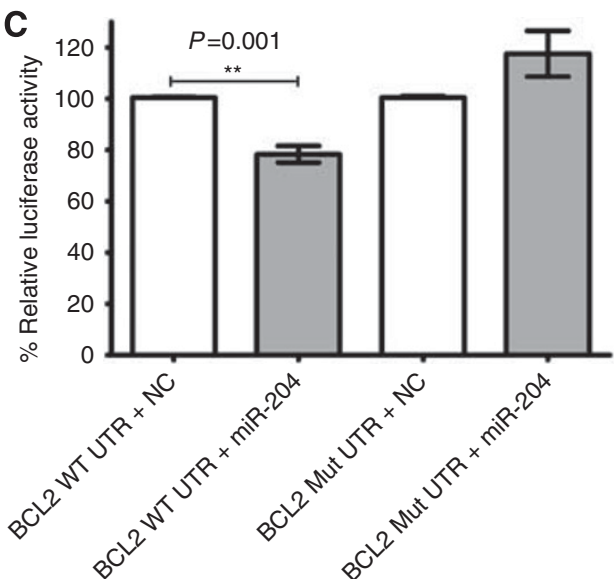

F

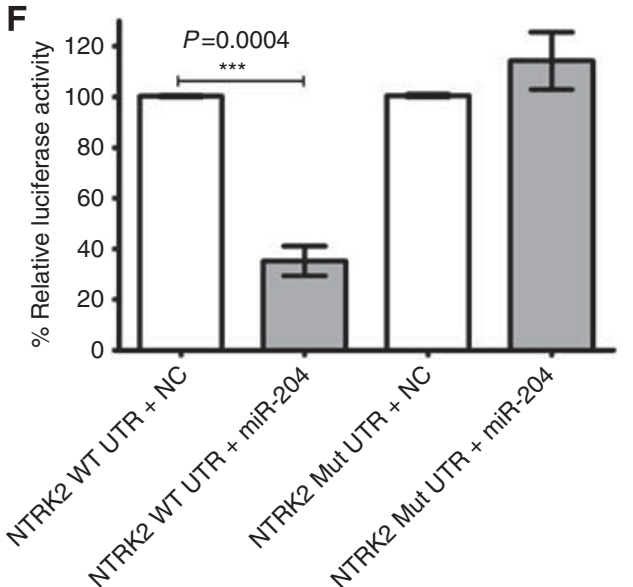

Figure 4 BCL2 and NTRK2 are direct targets of miR-204. Kelly cells were transfected with miR-204 mimics or scrambled negative control (scrambled NC) oligonucleotides. Graphed data are mean values \pm s.e.m. of at least three independent experiments. (A) Conserved 8-mer seed match with hsa-miR-204 in BCL2 3' UTR. (B) BCL2 mRNA relative expression to controls was determined by RQ-PCR at 24, 72 and 96 h post transfection, and BCL2 protein levels determined by western blot following total protein extraction at $48 \mathrm{~h}$. (C) Kelly cells were cotransfected with miR-204 mimics or scrambled NC and either wild-type (WT) or mutated (mut) BCL2 3'-UTR reporter constructs. Luciferase activity was determined $48 \mathrm{~h}$ post transfection. (D) Conserved 8-mer seed match with hsa-miR-204 in NTRK2 $3^{\prime}$ UTR. (E) Following transfection, Kelly cells were treated with $5 \mu \mathrm{M}$ ATRA for $48 \mathrm{~h}$ to induce full-length NTRK2 expression. NTRK2 mRNA expression relative to controls was determined by RQ-PCR at 72 and $96 \mathrm{~h}$ post transfection, and NTRK2 protein levels determined by western blot following total protein extraction at $72 \mathrm{~h}$. (F) Kelly cells were cotransfected with miR-204 mimics or scrambled NC and either WT or mutant NTRK2 3'-UTR reporter constructs. Luciferase activity was determined $48 \mathrm{~h}$ post transfection.

sensitivity to CDDP in neuroblastoma cells in vitro were not contributed to NTRK2 targeting in these cell lines. However, NTRK2 is associated with poor survival in neuroblastoma by promoting cell survival and chemotherapy resistance through the PI3K/AKT pathway, which is a well-established mechanism of resistance in neuroblastoma patients. We conclude that miR-204 directly targets the $3^{\prime}$ UTR of both BCL2 and NTRK2, two distinct and known mechanisms of increased resistance to chemotherapy in neuroblastoma.

\section{DISCUSSION}

Resistance to conventional chemotherapy remains a significant obstacle in the successful treatment of high-risk neuroblastoma, and for the most part the mechanisms of relapse and resistance remain poorly understood. In this report, we provide the first evidence of the role of miR-204 in increasing cancer cell sensitivity to chemotherapeutic drugs, providing a biological rationale for why lower expression of this miRNA in neuroblastoma patient tumours is significantly associated with poor survival. Here, we have identified and experimentally validated two novel targets of miR-204, NTRK2 and BCL2, both encoding cellular pro-survival effectors that are involved with increased resistance to chemotherapy in neuroblastoma. While targeting of BCL2 by several different miRNAs including miR-497, miR-181b, miR-15b, and miR-16 and the role in chemoresistance has been well described in different cancers, to our knowledge miRNA targeting of full-length NTRK2 has not been previously observed (Xia and Zhang, 2008; Lam et al, 2010; Zhu et al, 2010, 2012).

The characterisation of miR-204 functions, to date, has been limited, although several mRNA targets have been identified that are important in normal cell development, including MEIS1, HOXA9, MEIS2, RUNX2, and SIRT1 (Garzon et al, 2008; Conte et al, 2010; Huang et al, 2010; Saunders et al, 2010). miR-204 has been reported to act as a tumour suppressor in a variety of cancers through different mechanisms, including suppression of tumour growth via inhibition of macroautophagy in renal clear cell carcinoma, and suppression of invasion in endometrial cancer and squamous cell carcinoma (Lee et al, 2010; Chung et al, 2012; Mikhaylova et al, 2012). In the case of endometrial cancer, miR-204 was determined to regulate cell migration and invasion 
by targeting the FOXC1 gene. Similarly, this miRNA reduced migration, invasion, and the formation of metastatic tumours in models of squamous cell carcinoma but had no effect on proliferation or viability. In contrast, a recent publication by Gong et al (2012) demonstated that miR-204 expression in malignant peripheral nerve sheath tumour significantly reduced cellular proliferation in vitro.

Considering our observed results, a recent study of particular interest was by $\mathrm{Li}$ et al (2011) who suggested that miR-204 might contribute to the regulation of cell survival under stress conditions in human trabecular meshwork cells through validated targeting of the anti-apoptotic proteins BCL2L2 and $B I R C 2$. With regard to this role of miR-204 in regulating cell survival, Chen et al had previously demonstrated that miR-204 overexpression in cholangiocarcinoma cell lines resulted in significant reduction of detectable BCL2 protein levels, although direct targeting of miR-204 with the $3^{\prime}$ UTR of BCL2 was not demonstrated (Chen et al, 2009).

BCL2 has a critical role in ensuring the survival of early developing cell types and is strongly expressed in the developing sympathetic nervous system (Bashamboo et al, 2006; Hoehner et al, 1998). Castle et al (1993) determined that BCL2 protein was detectable in approximately a third of neuroblastoma tumours at diagnosis, and in $>80 \%$ of tumours following treatment, and was significantly associated with poor prognosis. Furthermore, the same group determined that BCL2 association with poor survival results from increased resistance to chemotherapy-induced apoptosis in neuroblastoma (Dole et al, 1994). In agreement with these observations, we showed that siRNA knockdown of BCL2 in neuroblastoma cells resulted in a significant increase in apoptosis levels in response to cisplatin and etoposide treatment. Similarly, modest yet statistically significant increased apoptosis levels were observed in cells overexpressing miR-204 following cisplatin or etoposide treatment. That we also demonstrated that miR-204 directly targets the $3^{\prime}$ UTR of $B C L 2$, and effectively reduces BCL2 protein levels in neuroblastoma cell lines, lends further credibility to our hypothesis that miR-204 represents a significant determinant of response to therapy in neuroblastoma. We suggest that the higher apoptosis levels induced by siRNA knockdown of BCL2 as opposed to miR-204-induced apoptosis levels is due in part to more effective targeting of BCL2 by siRNA, as multiple target sites might be competing for miR-204 binding. Lamers et al (2012) recently described that $B C L 2$ expression is highly upregulated in neuroblastoma tumours compared with normal controls and other cancers, but that these high levels of BCL2 are not observed in a majority of neuroblastoma cell lines, and knockdown of BCL2 in low-expressing cell lines results in subtle or little effect on apoptosis. This is consistent with our observation that in the absence of cisplatin, siRNA knockdown of BCL2 had no significant effect on NB1691 cell lines and only a modest increase in apoptosis levels in Kelly cell lines. Although we determined that BCL2 expression levels were readily detectable in our cell lines, it is worth considering that these levels may not be reflective of the high levels in patient tumours and that regulation of BCL2 protein in vivo may represent an even more dramatic phenotypic effect than we observed in vitro.

NTRK2 is also a well-established pro-survival oncogene in neuroblastoma, signalling the activation of the PI3K/AKT pathway, a significant mechanism of drug resistance in neuroblastoma (Bender et al, 2011). NTRK2 is preferentially expressed in the brain and peripheral nervous system and, similar to $B C L 2$, is essential for normal neuronal cell survival during development. Both $N T R K 2$, and its ligand, BDNF are expressed at high levels in clinically unfavourable neuroblastoma, promoting cell survival and treatment resistance (Nakagawara et al, 1994; Ho et al, 2002; Jaboin et al, 2003). Interestingly, the seed region for miR-204 occurs only in the $3^{\prime}$ UTR of the full-length variant of NTRK2 (as opposed to truncated versions). We determined that miR-204 specifically targets this $3^{\prime}$ UTR of NTRK2 and ectopic expression of miR-204 results in a significant reduction of full-length NTRK2 protein, providing evidence of another distinct role of miR-204 in response to therapy and further highlighting the importance of miR-204 expression in neuroblastoma.

In conclusion, miR-204 has emerged as an independent predictor of survival in neuroblastoma, functioning, at least in part, through direct targeting and downregulation of key chemotherapy resistance proteins NTRK2 and BCL2. The investigation of additional targets of miR-204, which may further explain a tumour suppressor role in neuroblastoma, is warranted. The upregulation of miR-204 in tumours could be envisioned as a potential method for increasing sensitivity of neuroblastoma cells to chemotherapy in vivo. In this regard, we have recently demonstrated nanoparticle-mediated targeted delivery of tumour suppressive miRNA to orthotopic xenograft tumours in a murine disease model (Tivnan et al, 2012). Further studies of miR-204 as a potential prognostic marker in a much larger tumour cohort is also warranted and might eventually allow for more refined therapy stratification.

\section{ACKNOWLEDGEMENTS}

This work was supported in part by the Children's Medical and Research Foundation, Dublin, Ireland, Science Foundation Ireland (07/IN.1/B1776) and the NIH (5R01CA127496).

Supplementary Information accompanies the paper on British Journal of Cancer website (http://www.nature.com/bjc)

\section{REFERENCES}

Bashamboo A, Taylor AH, Samuel K, Panthier JJ, Whetton AD, Forrester LM (2006) The survival of differentiating embryonic stem cells is dependent on the SCF-KIT pathway. J Cell Sci 119: 3039-3046

Bender A, Opel D, Naumann I, Kappler R, Friedman L, von Schweinitz D, Debatin KM, Fulda S (2011) PI3K inhibitors prime neuroblastoma cells for chemotherapy by shifting the balance towards pro-apoptotic Bcl-2 proteins and enhanced mitochondrial apoptosis. Oncogene 30: 494-503

Bray I, Bryan K, Prenter S, Buckley PG, Foley NH, Murphy DM, Alcock L, Mestdagh P, Vandesompele J, Speleman F, London WB, McGrady PW, Higgins DG, O'Meara A, O'Sullivan M, Stallings RL (2009) Widespread dysregulation of miRNAs by MYCN amplification and chromosomal imbalances in neuroblastoma: association of miRNA expression with survival. PLoS One 4: e7850

Bray I, Tivnan A, Bryan K, Foley NH, Watters KM, Tracey L, Davidoff AM, Stallings RL (2011) MicroRNA-542-5p as a novel tumor suppressor in neuroblastoma. Cancer Lett 303: 56-64
Brodeur GM (2003) Neuroblastoma: biological insights into a clinical enigma. Nat Rev Cancer 3: 203-216

Buckley PG, Alcock L, Bryan K, Bray I, Schulte JH, Schramm A, Eggert A, Mestdagh P, De Preter K, Vandesompele J, Speleman F, Stallings RL (2010) Chromosomal and microRNA expression patterns reveal biologically distinct subgroups of 11q- neuroblastoma. Clin Cancer Res 16: 2971-2978

Castle VP, Heidelberger KP, Bromberg J, Ou X, Dole M, Nunez G (1993) Expression of the apoptosis-suppressing protein bcl-2, in neuroblastoma is associated with unfavorable histology and N-myc amplification. Am J Pathol 143: 1543-1550

Charlet J, Schnekenburger M, Brown KW, Diederich M (2012) DNA demethylation increases sensitivity of neuroblastoma cells to chemotherapeutic drugs. Biochem Pharmacol 83: 858-865

Chen L, Yan HX, Yang W, Hu L, Yu LX, Liu Q, Li L, Huang DD, Ding J, Shen F, Zhou WP, Wu MC, Wang HY (2009) The role of microRNA 
expression pattern in human intrahepatic cholangiocarcinoma. $J$ Hepatol 50: $358-369$

Chen Y, Stallings RL (2007) Differential patterns of microRNA expression in neuroblastoma are correlated with prognosis, differentiation, and apoptosis. Cancer Res 67: 976-983

Chung TK, Lau TS, Cheung TH, Yim SF, Lo KW, Siu NS, Chan LK, Yu MY, Kwong J, Doran G, Barroilhet LM, Ng AS, Wong RR, Wang VW, Mok SC, Smith DI, Berkowitz RS, Wong YF (2012) Dysregulation of microRNA204 mediates migration and invasion of endometrial cancer by regulating FOXC1. Int J Cancer 130: 1036-1045

Cohn SL, Pearson AD, London WB, Monclair T, Ambros PF, Brodeur GM, Faldum A, Hero B, Iehara T, Machin D, Mosseri V, Simon T, Garaventa A, Castel V, Matthay KK (2009) The International Neuroblastoma Risk Group (INRG) classification system: an INRG Task Force report. J Clin Oncol 27: 289-297

Conte I, Carrella S, Avellino R, Karali M, Marco-Ferreres R, Bovolenta P, Banfi S (2010) miR-204 is required for lens and retinal development via Meis2 targeting. Proc Natl Acad Sci USA 107: 15491-15496

De Preter K, Mestdagh P, Vermeulen J, Zeka F, Naranjo A, Bray I, Castel V, Chen C, Drozynska E, Eggert A, Hogarty MD, Izycka-Swieszewska E, London WB, Noguera R, Piqueras M, Bryan K, Schowe B, van Sluis P, Molenaar JJ, Schramm A, Schulte JH, Stallings RL, Versteeg R, Laureys G, Van Roy N, Speleman F, Vandesompele J (2011) miRNA expression profiling enables risk stratification in archived and fresh neuroblastoma tumor samples. Clin Cancer Res 17: 7684-7692

Dickson PV, Hamner B, Ng CY, Hall MM, Zhou J, Hargrove PW, McCarville $\mathrm{MB}$, Davidoff AM (2007) In vivo bioluminescence imaging for early detection and monitoring of disease progression in a murine model of neuroblastoma. J Pediatr Surg 42: 1172-1179

Dole M, Nunez G, Merchant AK, Maybaum J, Rode CK, Bloch CA, Castle VP (1994) Bcl-2 inhibits chemotherapy-induced apoptosis in neuroblastoma. Cancer Res 54: 3253-3259

Foley NH, Bray I, Watters KM, Das S, Bryan K, Bernas T, Prehn JH, Stallings RL (2011) MicroRNAs 10a and $10 \mathrm{~b}$ are potent inducers of neuroblastoma cell differentiation through targeting of nuclear receptor corepressor 2. Cell Death Differ 18: 1089-1098

Foley NH, Bray IM, Tivnan A, Bryan K, Murphy DM, Buckley PG, Ryan J, O'Meara A, O'Sullivan M, Stallings RL (2010) MicroRNA-184 inhibits neuroblastoma cell survival through targeting the serine/threonine kinase AKT2. Mol Cancer 9: 83

Fontana L, Fiori ME, Albini S, Cifaldi L, Giovinazzi S, Forloni M, Boldrini R, Donfrancesco A, Federici V, Giacomini P, Peschle C, Fruci D (2008) Antagomir-17-5p abolishes the growth of therapy-resistant neuroblastoma through p21 and BIM. PLoS One 3: e2236

Garzon R, Garofalo M, Martelli MP, Briesewitz R, Wang L, FernandezCymering C, Volinia S, Liu CG, Schnittger S, Haferlach T, Liso A, Diverio D, Mancini M, Meloni G, Foa R, Martelli MF, Mecucci C, Croce CM, Falini B (2008) Distinctive microRNA signature of acute myeloid leukemia bearing cytoplasmic mutated nucleophosmin. Proc Natl Acad Sci USA 105: 3945-3950

Giovannetti E, Erozenci A, Smit J, Danesi R, Peters GJ (2012) Molecular mechanisms underlying the role of microRNAs (miRNAs) in anticancer drug resistance and implications for clinical practice. Crit Rev Oncol Hematol 81: 103-122

Gong M, Ma J, Li M, Zhou M, Hock JM, Yu X (2012) MicroRNA-204 critically regulates carcinogenesis in malignant peripheral nerve sheath tumors (2012). Neuro Oncol; e-pub ahead of print 19 June 2012; PMID:22718995

Ho R, Eggert A, Hishiki T, Minturn JE, Ikegaki N, Foster P, Camoratto AM, Evans AE, Brodeur GM (2002) Resistance to chemotherapy mediated by TrkB in neuroblastomas. Cancer Res 62: 6462-6466

Hoehner JC, Hedborg F, Eriksson L, Sandstedt B, Grimelius L, Olsen L, Pahlman S (1998) Developmental gene expression of sympathetic nervous system tumors reflects their histogenesis. Lab Invest 78: 29-45

Huang J, Zhao L, Xing L, Chen D (2010) MicroRNA-204 regulates Runx2 protein expression and mesenchymal progenitor cell differentiation. Stem Cells 28: 357-364

Jaboin J, Hong A, Kim CJ, Thiele CJ (2003) Cisplatin-induced cytotoxicity is blocked by brain-derived neurotrophic factor activation of TrkB signal transduction path in neuroblastoma. Cancer Lett 193: 109-114

Jaboin J, Kim CJ, Kaplan DR, Thiele CJ (2002) Brain-derived neurotrophic factor activation of TrkB protects neuroblastoma cells from chemotherapy-induced apoptosis via phosphatidylinositol 3'-kinase pathway. Cancer Res 62: 6756-6763
Lam LT, Lu X, Zhang H, Lesniewski R, Rosenberg S, Semizarov D (2010) A microRNA screen to identify modulators of sensitivity to BCL2 inhibitor ABT-263 (navitoclax). Mol Cancer Ther 9: 2943-2950

Lamers F, Schild L, den Hartog IJ, Ebus ME, Westerhout EM, Ora I, Koster J, Versteeg R, Caron HN, Molenaar JJ (2012) Targeted BCL2 inhibition effectively inhibits neuroblastoma tumour growth. Eur J Cancer; e-pub ahead of print 24 February 2012; PMID: 22366560

Lee Y, Yang X, Huang Y, Fan H, Zhang Q, Wu Y, Li J, Hasina R, Cheng C, Lingen MW, Gerstein MB, Weichselbaum RR, Xing HR, Lussier YA (2010) Network modeling identifies molecular functions targeted by miR-204 to suppress head and neck tumor metastasis. PLoS Comput Biol 6: e1000730

Li G, Luna C, Qiu J, Epstein DL, Gonzalez P (2011) Role of miR-204 in the regulation of apoptosis, endoplasmic reticulum stress response, and inflammation in human trabecular meshwork cells. Invest Ophthalmol Vis Sci 52: 2999-3007

Lynch J, Fay J, Meehan M, Bryan K, Watters KM, Murphy DM, Stallings RL (2012) MiRNA-335 suppresses neuroblastoma cell invasiveness by direct targeting of multiple genes from the non-canonical TGF-beta signalling pathway. Carcinogenesis 33: 976-985

Manohar CF, Bray JA, Salwen HR, Madafiglio J, Cheng A, Flemming C, Marshall GM, Norris MD, Haber M, Cohn SL (2004) MYCN-mediated regulation of the MRP1 promoter in human neuroblastoma. Oncogene 23: $753-762$

Maris JM (2010) Recent advances in neuroblastoma. N Engl J Med 362: 2202-2211

Maris JM, Hogarty MD, Bagatell R, Cohn SL (2007) Neuroblastoma. Lancet 369: $2106-2120$

Matsumoto K, Wada RK, Yamashiro JM, Kaplan DR, Thiele CJ (1995) Expression of brain-derived neurotrophic factor and p145TrkB affects survival, differentiation, and invasiveness of human neuroblastoma cells. Cancer Res 55: 1798-1806

Mestdagh P, Fredlund E, Pattyn F, Schulte JH, Muth D, Vermeulen J, Kumps C, Schlierf S, De Preter K, Van Roy N, Noguera R, Laureys G, Schramm A, Eggert A, Westermann F, Speleman F, Vandesompele J (2010) MYCN/c-MYC-induced microRNAs repress coding gene networks associated with poor outcome in MYCN/c-MYC-activated tumors. Oncogene 29: 1394-1404

Middlemas DS, Kihl BK, Zhou J, Zhu X (1999) Brain-derived neurotrophic factor promotes survival and chemoprotection of human neuroblastoma cells. J Biol Chem 274: 16451-16460

Mikhaylova O, Stratton Y, Hall D, Kellner E, Ehmer B, Drew AF, Gallo CA, Plas DR, Biesiada J, Meller J, Czyzyk-Krzeska MF. VHL-regulated MiR204 suppresses tumor growth through inhibition of LC3B-mediated autophagy in renal clear cell carcinoma (2012) Cancer Cell 21: 532-546

Nakagawara A, Azar CG, Scavarda NJ, Brodeur GM (1994) Expression and function of TRK-B and BDNF in human neuroblastomas. Mol Cell Biol 14: 759-767

Porro A, Haber M, Diolaiti D, Iraci N, Henderson M, Gherardi S, Valli E, Munoz MA, Xue C, Flemming C, Schwab M, Wong JH, Marshall GM, Della Valle G, Norris MD, Perini G (2010) Direct and coordinate regulation of ATP-binding cassette transporter genes by Myc factors generates specific transcription signatures that significantly affect the chemoresistance phenotype of cancer cells. J Biol Chem 285: 19532-19543

Saunders LR, Sharma AD, Tawney J, Nakagawa M, Okita K, Yamanaka S, Willenbring $\mathrm{H}$, Verdin E (2010) miRNAs regulate SIRT1 expression during mouse embryonic stem cell differentiation and in adult mouse tissues. Aging (Albany NY) 2: 415-431

Schulte JH, Schowe B, Mestdagh P, Kaderali L, Kalaghatgi P, Schlierf S, Vermeulen J, Brockmeyer B, Pajtler K, Thor T, de Preter K, Speleman F, Morik K, Eggert A, Vandesompele J, Schramm A (2010) Accurate prediction of neuroblastoma outcome based on miRNA expression profiles. Int J Cancer 127: 2374-2385

Teitz T, Wei T, Valentine MB, Vanin EF, Grenet J, Valentine VA, Behm FG, Look T, Lahiti JM, Kidd VJ (2000) Caspase 8 is deleted or silenced preferentially in childhood neuroblastomas with amplification of MYCN. Nat Med 6: 529-553

Tivnan A, Orr WS, Gubala V, Nooney R, Williams DE, McDonagh C, Prenter S, Harvey H, Domingo-Fernández R, Bray IM, Piskareva $\mathrm{O}$, Ng CY, Lode HN, Davidoff AM, Stallings RL (2012) Inhibition of neuroblastoma tumor growth by targeted delivery of microRNA-34a using anti-disialoganglioside $\mathrm{GD}(2)$ coated nanoparticles. PLoS One 7: e38129 
Welch C, Chen Y, Stallings RL (2007) MicroRNA-34a functions as a potential tumor suppressor by inducing apoptosis in neuroblastoma cells. Oncogene 26: 5017-5022

Xia L, Zhang D, Du R, Pan Y, Zhao L, Sun S, Hong L, Liu J, Fan D (2008) miR-15b and miR-16 modulate multidrug resistance by targeting BCL2 in human gastric cancer cells. Int J Cancer 123: 372-379

Yu AL, Gilman AL, Ozkaynak MF, London WB, Kreissman SG, Chen HX, Smith M, Anderson B, Villablanca JG, Matthay KK, Shimada $H$, Grupp SA, Seeger R, Reynolds CP, Buxton A, Reisfeld RA, Gillies SD,
Cohn SL, Maris JM, Sondel PM, Children's Oncology Group (2010) Anti-GD2 antibody with GM-CSF, interleukin-2, and isotretinoin for neuroblastoma. N Engl J Med 363: 1324-1334

Zhu W, Shan X, Wang T, Shu Y, Liu P (2010) miR-181b modulates multidrug resistance by targeting BCL2 in human cancer cell lines. Int J Cancer 127: 2520-2529

Zhu W, Xu H, Zhu D, Zhi H, Wang T, Wang J, Jiang B, Shu Y, Liu P (2012) miR-200bc/429 cluster modulates multidrug resistance of human cancer cell lines by targeting BCL2 and XIAP. Cancer Chemother Pharmacol 69: 723-731

This work is published under the standard license to publish agreement. After 12 months the work will become freely available and the license terms will switch to a Creative Commons Attribution-NonCommercial-Share Alike 3.0 Unported License. 